\title{
EX-PRESOS POLÍTICOS E A MEMÓRIA SOCIAL DA TORTURA NO PARANÁ (1964-1978), de Sílvia Calciolari ${ }^{1}$
}

\author{
Viviane Rodrigues Darif Saldanhas ${ }^{2}$
}

- Enviado em 30/01/2016

- Aprovado em 14/02/2016

Nesse trabalho de dissertação, Calciolari (2004) visa realizar a sistematização da memória de ex- presos políticos, tendo como ponto central a prática da tortura durante a repressão no Estado do Paraná. Para isso, a autora parte da vigência da Lei 11.255/95, onde houve a criação de um espaço de memória, para que este grupo pudesse realizar o registro de sua história, de forma que promovessem uma espécie de confrontação com relação à versão oficial. Uma vez que durante o período de Regime Militar, o Estado brasileiro adotou o papel tanto de implementar o desenvolvimento econômico quanto da manutenção da ordem política interna. A sustentação de tal objetivo perdurou pelo período de duas décadas, onde dói utilizado para este fim uma "história oficial" que objetivava legitimar e justificar a ação de uma política interna repressiva.

Assim, foram realizadas análises dos documentos de 175 dossiês deferidos pela Comissão Especial de Indenização composta por nove membros designados pela Lei que foram reunidos através da Comissão Especial de Indenização, que realizou a analise dos processos de homens e mulheres que foram custodiados pelo Estado do Paraná em seus prédios públicos entre 1961 e 1979. Dessa forma, Calciolari (2004) ressalta que esta revela dados como a determinação de vigilância, coleta de informações, prisão e mesmo uma espécie de institucionalização da tortura, esta praticada por meio de agentes em prédios públicos, como também estabelecer, através desses documentos,

\footnotetext{
${ }^{1}$ Dissertação de autoria de Silvia Calciolari, defendida no Programa de Pós-Graduação em Sociologia da UFPR, na linha Sociedade e Estado, em 2004, sob orientação do Prof. Dr. Ricardo Costa de Oliveira. Versão completa disponível na Biblioteca Digital da UFPR - http://dspace.c3sl.ufpr.br:8080/dspace/bitstream/handle/1884/32912/R\%20-\%20D\%20\%20SILVIA\%20CALCIOLARI.pdf?sequence=1
}

${ }^{2}$ Graduada em Ciências Sociais e mestre em Sociologia pela UFPR Endereço eletrônico: vivianedarif@gmail.com 
um perfil conciso dos militantes políticos que foram perseguidos pela repressão, a localização desses prédios públicos, as formas e técnicas de tortura utilizadas pelos agentes públicos e ainda os responsáveis pela implantação da política de Segurança Nacional no Paraná durante o período.

Calciolari (2004), ao introduzir o Estado do Paraná neste panorama, também traz a tona episódios e figuras de uma peleja que foi travada no Brasil e que teve sérios desdobramentos nesse estado do sul do país. Assim, no segundo capítulo dessa dissertação, intitulado "A Produção Social Da Memória" a autora traça um panorama com relação a Lei 11.255/95, e ainda a forma com que a pesquisa foi realizada, além de pautar como objetivo principal a análise dos relatos contidos nos dossiês analisados pela Comissão Especial, em especial os circunstanciais e espontâneos dos expresos políticos para que fosse possível reconstruir a ação da repressão e seus desdobramentos no Paraná.

Por meio dessas memórias, ressalta que ainda que passados 40 anos da implantação do Regime Militar no Brasil, ainda é possível perceber por parte dos ex-presos políticos uma memória fortemente marcada pelo trauma da repressão. E ainda que muitos ainda levam na lembrança as sequelas de toda a violência e ferocidade empregada pelos agentes do Estado autoritário. Conforme, Calciolari (2004), por meio da pesquisa foi possível ainda contatar que houve três grandes momentos de ação repressiva no Paraná, 1964, 1970 e 1975. E durante a pesquisa, ainda foi possível verificar que algumas pessoas foram presas pela polícia política mais de uma vez.

No capítulo 3, chamado de "O Estado e a Tortura" como referência principal a autora utiliza a proposta sociológica de Max Weber com a finalidade de estabelecer uma discussão sobre o Estado enquanto uma instituição forte, centralizadora e dominadora da cena social. Já no capítulo 4, “A Institucionalização da Tortura", Calciolari (2004), inicia tratando do sobre o caráter institucional da tortura, perpassa sobre a a natureza pública da tortura e as manifestações de intolerância até chegar ao chamado "o esquadrão da morte".

Em seguida, Calciolari (2004), nos apresenta o capítulos 5 “A Repressão no Paraná”, que faz um apanhado desde o reconhecimento dos mortos até a indenização dos vivos, passando pela elaboração da lei 11.225, que teve como base a lei federal 9.140/95. Além do trabalho da Comissão Especial, que iniciou seus trabalhos em 10 de dezebro de 1997, em uma solenidade que marcou ainda o $49^{\circ}$ aniversário da Declaração Universal dos Direitos Humanos. E conforma a autora,

Uma das principais preocupações do presidente da Comissão de Indenização aos ex-presos políticos do Estado do Paraná, o Ouvidor João Elias de Oliveira,manifestada já nas primeiras reuniões, era não transformar a comissão numa entidadeburocrática. Isto porque muitos ex-presos políticos estavam encontrando dificuldadespara conseguir as provas documentais de que ficaram sob a guarda de algum órgão ou autoridade vinculada ao poder central. Isto graças à transferência do ônus da prova para o requerente. $\mathrm{O}$ próprio estatuto de funcionamento da Comissão Especial determinava, no item 3, que "os interessados 
deverão requerer à Comissão o pedido de indenização, instruindo-o com os dados e documentos pessoais completos, relato das ocorrências e outras informações necessárias". Era preciso, segundo o presidente, que houvesse o mínimo de sedimentação documental; ou seja, para aqueles que no arquivo do Dops constava a ficha e o tempo em que ficaram detidos na Prisão Provisória do Ahu não havia necessidade de informações complementares, como por exemplo da auditoria da 5a Região Militar. (CALCIOLARI, 2004, p. 75).

Mas segundo Calciolari (2004), o maior momento da Comissão Especial ocorreu ao concederem aos perseguidos políticos a possibilidade de não apenas reavivarem a memória, mas de trazerem à tona suas falas e relatos, uma vez que até então, o monopólio e a "legitimidade" de fala cabia apenas ao Estado, por meio de seus agentes, que eram especialmente designados (chamados de arapongas) a procurar, obter e minutar as informações dos considerados "oposicionistas". Assim, a autora ressalta que as "fichas da Delegacia de Ordem Política e Social são a prova cabal e incontestável do aparato burocrático de espionagem idealizado, reproduzido e mantido pelo Regime Militar" (CALCIOLARI, 2004, p. 77).

E por mais espantoso que possa parecer, as mesmas informações presentes nas fichas que serviram à Ditadura, e que em algum tempo atrás poderiam ser utilizadas para motivar alguma vigília, prisão, interrogatório e ainda a execração por agentes públicos, possuía agora outra serventia. E assim, as fichas do antigo Dops foram utilizadas como principal documento e prova apresentada pelos requerentes aos benefícios da Lei 11.255/95. Assim, Calciolari (2004) relata que é importante observar que o documento apresenta detalhadas informações sobre a atividade política e social dos investigados, além de informações, que em alguns casos, iniciavam na década de 1950 e somente se encerravam em meados de 1986. Dessa forma "a partir do que constava nas anotações feitas nas fichas, os ex-presos políticos puderam instrumentar seus pedidos de indenização, ao mesmo tempo em que reencamaram a sua memória, organizaram seu passado e sua história" (CALCIOLARI, 2004, p. 78).

Assim sendo, é possível dizer que ocorreu um significativo avanço com relação ao

[...] reconhecimento da relevância do serviço prestado ao país, ao explicitar a existência e a prática de tortura psicológica, que não deixa seqüelas físicas visíveis mas um trauma praticamente insuperável. Muitos dos que perderam familiares, amigos e conhecidos naquela época e conseguiram sobreviver às torturas, sucumbiram diante da sociedade, sofrendo o preconceito de terem sido perseguidos políticos, passado pelo sistema carcerário, embora na condição de preso político. Alguns se recuperaram, conforme puderam demonstrar. Outros, mal conseguiam articular de forma organizada seu passado, sua história. Os próprios integrantes da Comissão Especial foram unânimes em considerar que "independente do tempo em que o ex-preso político permaneceu detido, o trauma permanece devido a vários fatores da violência ativa que existe e da recepção passiva de quem recebe a violência" 14. Assim, estaria fundamentada para efeito de concessão de pareceres que uma das características manifestadas pelo bloqueio emocional está na articulação verbal, com alguns tendo maior dificuldade em relatar as experiências vividas que outros. (CALCIOLARI, 2004, p. 79). 
E no penúltimo capitulo, o 6, cujo o título é "Memória da Tortura", a autora ressalta que o número de indivíduos que estavam entre 20 e 34 anos é representativo. E que estes de apresentavam como cidadãos com uma formação política já consolidada, inclusive que muitos já estavam na Universidade, ou já se apresentavam como profissionais, 53\% dos militantes já eram casados. Ou seja, muitos já tinham uma família constituída, revelando um retrato de um Brasil que apresentavam consciência crítica de sua condição política. Essa consciência crítica já se ensejava no antigo $2^{\circ}$ Grau, através de importantes lideranças estudantis que assumiam para si uma certa responsabilidade em fornecer e garantir elementos teóricos para a reflexão.

Além disso, é possível perceber, por meio dos dados analisados por Calciolari (2004), que o movimento sindical mobilizava as ações dos militantes no Porto de Paranaguá e dos bancários do Banco do Brasil em 1964. Mas na década de 1970, o foco de resistência foi movimento estudantil e em 1975 foi a militância partidária o ponto central da ação da repressão no Estado.. E ainda, na leitura atenta dos documentos, alguns nomes são apontados pelos ex-presos políticos como autores das torturas praticadas nos prédios públicos do Paraná, em sua maioria pautados em sobrenomes como Almeida, Lisboa ou Diniz. A dissertação apresenta ainda diversos dados comparativos com relação à questão profissional e social dos presos políticos, além de excertos de falas e depoimentos que nos ajuda a compreender melhor a situação nesse período.

E por fim, ainda que passados 40 anos do golpe militar de 64, é possível perceber que a memória nacional apenas se transformou profundamente na última década. E que essa mudança apresenta uma ordem qualitativa, ou seja, ela altera a percepção e análise de alguns dos momentos bastante significativos da nossa história política recente. Uma dessas mudanças, conforme Calciolari (2004), "é o novo valor conferido aos brasileiros que ampararam a resistência e o enfrentamento com relação à ditadura, na atualidade nos deparamos com outro discurso eferente a memória nacional, onde ex-presos políticos”(p. 141). Estes ultrapassam o estigma de 'inimigos da pátria' adjetivo lhes atribuído por meio da versão oficial e passam a ser considerados 'heróis da resistência democrática'.

E com relação ao o final dos trabalhos da Comissão Especial, no Estado do Paraná, não estava sendo apenas legitimando o pagamento pecuniário com relação às indenizações foi dada voz aos ex-presos políticos, algo que ainda não havia sido feito. E foi essa "disposição em incorporar à memória nacional os dados mantidos no silêncio das lembranças das vítimas da repressão e nos documentos oficiais que coloca o Brasil na vanguarda em relação à defesa dos Direitos Humanos" (CALCIOLARI, 2004, p. 143). 